\title{
Use of environmental parameters in building envelope design
}

\author{
N. Nikolov \\ Department of Art, Architecture and Design, Lehigh University, USA
}

\begin{abstract}
Today the architectural profession sees its future in the interplay and balance between the natural and built environments and increasingly seeks to establish a functional interface between them. Influenced by the wide use and dependency on software and numerically-controlled fabrication technologies, novel and complex forms are often evaluated through performance criteria that emphasize the environmental and structural parameters that shape them. These trends in architectural design and construction offer designers, engineers, and contractors the unique opportunity to combine qualitative with quantitative research methods in addressing the environmental demands on buildings. This paper reports on the research, design development, and conclusions of a project involving the development of an exterior shading screen for an east-facing glass curtain wall façade of a small residence in eastern Pennsylvania. The screen is able to provide optimal shading over a pre-determined period of time, as well as optimal porosity to allow for natural light penetration and ventilation.

Keywords: environmental parametrics, parametric design, grasshopper, solar geometry, energy efficient design, exterior shading, building envelope design.
\end{abstract}

\section{Introduction}

Bridging the gap between nature and the built environment is a pre-historic preoccupation for mankind. The current trend of green design, which has established itself as the prominent paradigm of the last decade, seeks to establish a functional interface between the natural and the built environments and in doing so to improve building performance [1]. In contrast to the inclination by many in the $20^{\text {th }}$ century to see nature as an adverse factor to be excluded at all 
cost, the vast majority of today's architectural profession sees its future in the interplay and balance between the natural and built environments.

An equally important trend in today's architectural design and construction is the increased use and dependency on software and numerically-controlled fabrication technologies. Digital fabrication techniques, such as negative moulding, CNC milling, 3D printing, water jet, plasma, and laser-cutting have transformed the methodology of design. Computer-numerical-controlled (CNC) technologies have fostered a reciprocal relationship between the process of design and the act of making.

The above two trends offer designers and engineers a renewed opportunity to combine qualitative and quantitative research methods in harnessing computing and digital fabrication processes in addressing emergent environmental demands on the built environment.

\section{Thermal performance issues of facades}

In the United States, buildings consume $40 \%$ of primary energy and $72 \%$ of electricity consumption [2]. The majority of the electricity demand is lighting (almost 20\%) and heating and cooling (36\% and 8\%). Each of these energy demands is closely related to the building envelope, and can be decreased with efficient envelope design. The building envelope, a.k.a. building façade or building skin, is the most important subsystem of the building, serving as the link between all other components of the building system, such as structure, technical services, and the interior walls of the building [3].

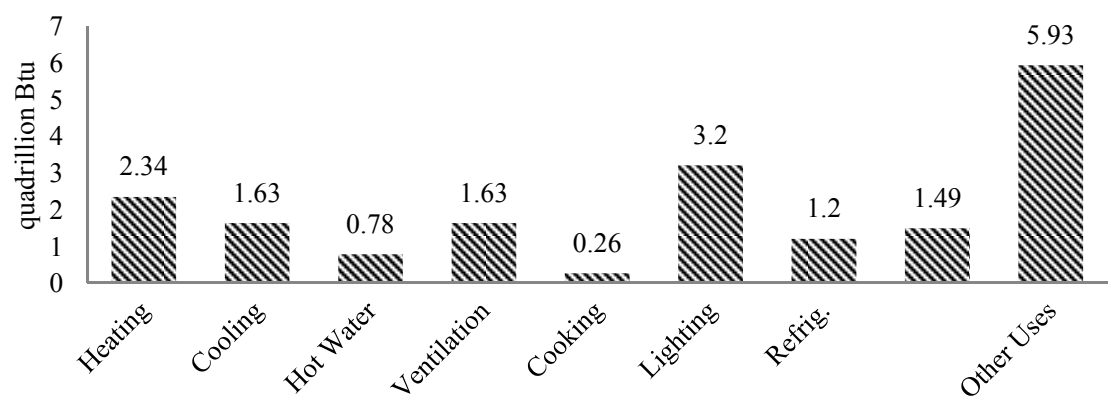

Figure 1: $\quad$ Commercial total end use energy consumption [4].

In 2011, the total energy consumption for lighting in commercial buildings was 3.2 quadrillion Btu (EIA [5]) (Figure 1), while the total end use energy consumption for lighting in residential buildings was 2.17 quadrillion Btu (Figure 2). (A British thermal unit (Btu) is a measure of the quantity of heat required to raise the temperature of 1 pound of liquid water by $1^{\circ} \mathrm{F}$ at the temperature that water has its greatest density (approximately $39^{\circ} \mathrm{F}$ ).) Of the combined 5.37 quadrillion Btu that the residential and commercial sectors have used for lighting, $25 \%$ can be attributed to the energy gains and losses related to 
fenestration elements. This makes 1.34 quadrillion Btu that was used to offset undesirable energy gains and losses related to doors, windows, and other fenestration (NFRC [6]) elements, usually deployed as part of building envelope design. (Fenestration is any opening in a building's envelope including windows, doors, and skylights.) This number represents $13.6 \%$ of the 39.97 quadrillion Btu consumed by the entire residential and commercial sectors in 2011 taken together. The potential for energy savings through targeted design is significant.

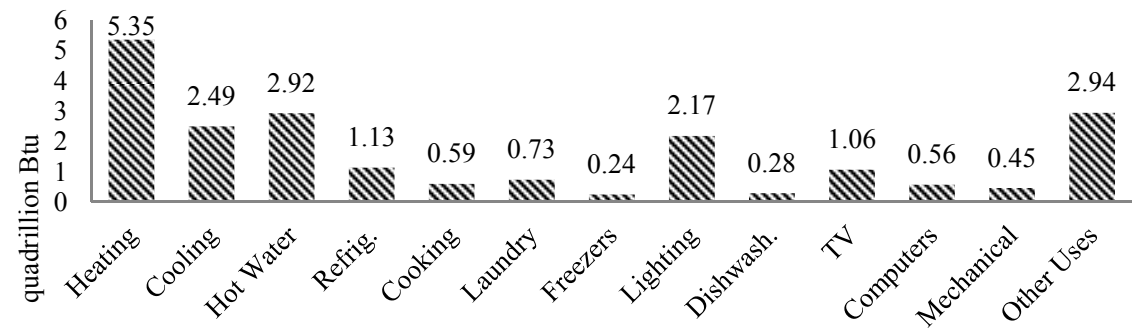

Figure 2: Residential total end use energy consumption.

The use of building fenestration as an energy asset rather than an energy burden in building construction is essential. Rather than merely providing interior enclosure with a view, envelope design should support the energy concept of the building and reduce its energy consumption. It should avoid overheating during the warm seasons and reduce heating loads during the cold seasons.

\section{Objective}

This research pursues the development of an algorithmic design for a façade shading component that utilizes model data from site conditions as a means to mitigate the adverse effects of solar heat gain on energy demand. The positive effect of solar heat gain during the cold season will be given consideration at subsequent stage of the project and will not be part of the design criteria outlined here.

\section{Design approach}

Present day parametric design software enables environmentally derived data to be incorporated seamlessly into the design process and be taken into account in the form-generation of building envelope components. The algorithmic modeling tool Grasshopper ${ }^{\circledR}$, a plug-in for the 3-dimensional NURBS (Non-Uniform Rational B-Splines (NURBS) are mathematical representations of 3-D geometry that accurately describe a wide range of curves, surfaces and solids [7]); modeling software Rhinoceros ${ }^{\mathrm{TM}}$, enables the design process to become more 
flexible and responsive by the interactive integration of environmentally driven parameters.

Using a specifically designed in Grasshopper ${ }^{\circledR}$ parametric algorithm, this research project will produce a design for a building envelope component, which is able to provide full shading over a pre-determined period of time, as well as optimal porosity to allow for natural light penetration and ventilation. The 3dimensional structure will be processed for construction using Rhinoceros $^{\mathrm{TM}}$. The geometry will be transferred into Computer Aided Design (CAD) software, such as Autodesk AutoCAD Architecture 2012, from where it can be processed for construction. A CNC-router will in the future be used to produce a prototype of the optimized building envelope component.

\subsection{The importance of shading systems}

When designing energy efficient buildings, solar radiation (a propagation of electromagnetic energy through space - this process is to be distinguished from other forms of energy transfer such as conduction and convection [8]) can be both an asset and a handicap. On one hand, energy from the sun can be harnessed and used to heat buildings and reduce utility costs. On the other hand, solar radiation also represents the largest source of heat gain in buildings, which can demand significant amounts of energy to keep a building cool.

A transparent east, south, or west-facing building skin without shading devices is fully exposed to radiation and is especially problematic. Efficient design of shading devices is imperative in climates where the exterior temperatures exceed the desired indoor temperature for extended periods of time. Direct sun light has smaller impact on exterior walls that on exterior fenestration due to the former's significantly higher thermal mass and inertia. Shortwave and long wave radiation, i.e. energy, is absorbed easily by exterior walls and is released at night, and thus mediating the impact of extreme changes in outside temperature. Insolation (solar radiation on the surface of the Earth - this term has been generally replaced by solar irradiance because of the confusion of the word with insulation [9]) heats up the interior through energy transmittance via the façade and the roof of a building. (Transmittance is the fraction or per cent of a particular frequency or wavelength of electromagnetic radiation that passes through a substance without being absorbed or reflected [10].) Not all of the energy gets transmitted; most of it gets absorbed by the material. The amount of absorption depends on the properties of the material and its color. (Absorption is when energy is captured by a substance, reducing the amount available [11].) Glass, on the other hand is almost transparent to radiation [12, p. 9]. Solar insolation directly heats up the interior surfaces and is the main contributor to heat gain. One strategy to mitigate this is by introducing reflective coating, whose increased effectiveness results from coloration and reduced transparency - leading to reduced visual properties and quality of light. With regard to visual quality the use of shading to protect the window area from direct insolation yields optimal results. 


\subsection{Shading types}

Shading devices can be systematized according to orientation and according to location. In regards to the first, most shading devices are oriented vertically or horizontally. In addition, either can be located on the interior of the glazing, in line with the glazing, and exterior to the building envelope (Figure 3 ). There is a high variety of shading devices on the market, yet of all can be said that interior shading devices are the least desirable since they act as radiators, having absorbed the short wave radiation and converted it to long wave radiation. Interior shading devices heat up the interior surfaces and the space between the window and the device through radiation and air convection. They should be rather classified as glare control devices [12, p. 10].

Shading installed within the window unit or fenestration system are of less interest in regards to efficiency of retrofitting and improving the energy performance of existing envelopes as their use requires the replacement of the fenestration components and their significant upfront cost in material and labour are prohibitive in many cases. Similar concern can be attributed to various screens integrated with the building envelope, etched glass, ventilated curtain walls, operable shutters, and automatic manipulators.

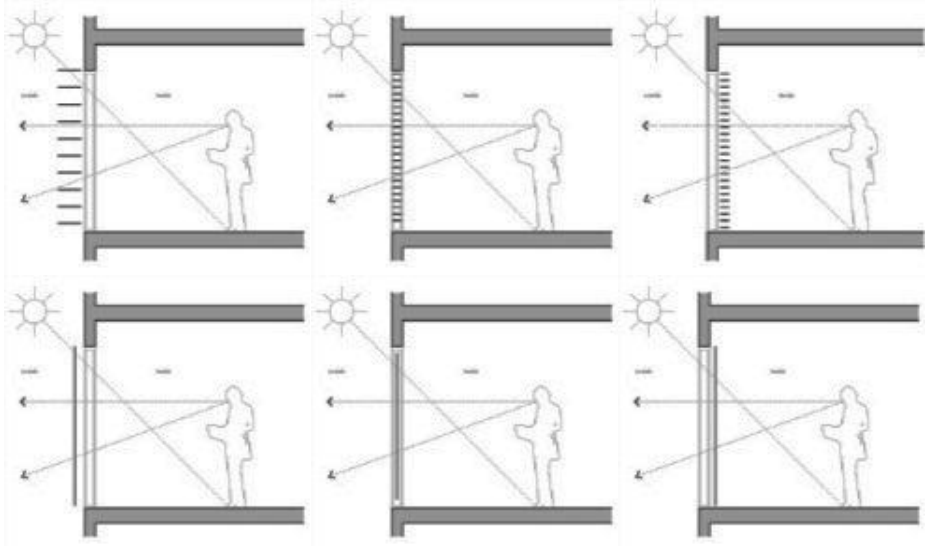

Figure 3: Types of shading devices: exterior horizontal, horizontal in glazing cavity, interior horizontal, exterior vertical, vertical in glazing cavity, interior vertical.

Exterior shading, on the other hand, can be designed with respect to precise local conditions and installed without disruption of building occupancy and in a variety of configurations. Weather conditions, such as air temperature swings, humidity, UV radiation, precipitation, and wind, can lead to higher production and installation costs as well as concerns for durability and maintenance.

In evaluating which shading device is most appropriate for a given situation, one must take into account its geographic location, its orientation with regard to the sun, and its performance with regard to the degree of visual contact as well as 
the degree of shading they provide throughout the year. The latter two criteria usually are seen to work against each other. I high amount of provided shading may lead to a low degree of visual contact and, conversely, a high degree of visual contact may result in poor shading performance.

\subsection{Preliminary design parameters}

For the purposes of testing our design approach we have selected a case study building of ubiquitous type, construction, and occupancy. It is located in the Lehigh Valley in Pennsylvania, USA. Built in 1959, it is a single family residence, rectangular perimeter, concrete block ground floor, light wood frame main floor construction, concrete slab foundation, wood joist floor and a flat EPDM roof. The building is oriented with its long side predominantly in the north-south direction and its shorter sides in the east-west directions. However, the east- and west-facing facades are $77 \%$ glazed, while only $12 \%$ of the north and south facades are glazed. Further, the building's latitude is $40^{\circ} 39^{\prime} 50^{\prime \prime} \mathrm{N}$, longitude is $75^{\circ} 22^{\prime} 0^{\prime \prime} \mathrm{W}$, and the altitude is $116.0 \mathrm{~m}$. Its north and south elevations are oriented $5.24^{\circ} \mathrm{N}$ (determined from [13]). The climate during the hot summer months from mid-June until mid-August is classified as warm humid.

The most undesirable orientation for glazing is towards those portions of the sky in which the sun is low in its daily path, i.e. towards the east and west. An analysis of the case study location leads to the conclusion that the worst case scenario is for east-facing glazing at 15 degrees from true east, based on average daily incident radiation on a vertical surface (Figure 4). The building's east façade, oriented at $5.24^{\circ} \mathrm{E}$ identifies it as most needing a shading solution.

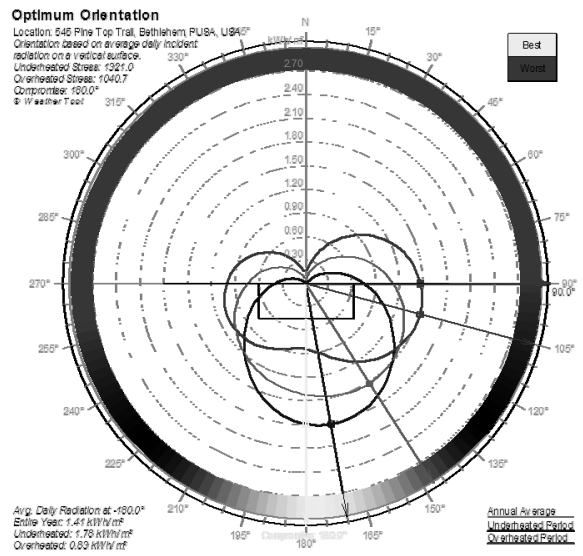

Figure 4: $\quad$ Optimum orientation, Weather Tool 2011, Autodesk Inc. 2010. 


\section{Shading criteria}

The main challenge for the designer is to control the quality of light and to avoid excessive sun exposure of the interior. At thermal comfort zone (this environmental temperature range is subjectively determined and commonly assumed to be $18.0^{\circ} \mathrm{C}$ to $26.0^{\circ} \mathrm{C}$ at relative humidity of $40-65 \%$ ) set at thermal neutrality, we have the maximum daily DBT (dry-bulb temperature - air temperature measured with a thermometer, similar to ambient temperature, to be distinguished from wet-bulb temperature measured by a psychrometer to determine relative humidity [14]) exceeding the upper limit of the comfort zone without more than a day interruption for the period of June 19-August 22. For the general purposes of this project we exclude the single day below comfort day of July 12 (Figure 5).

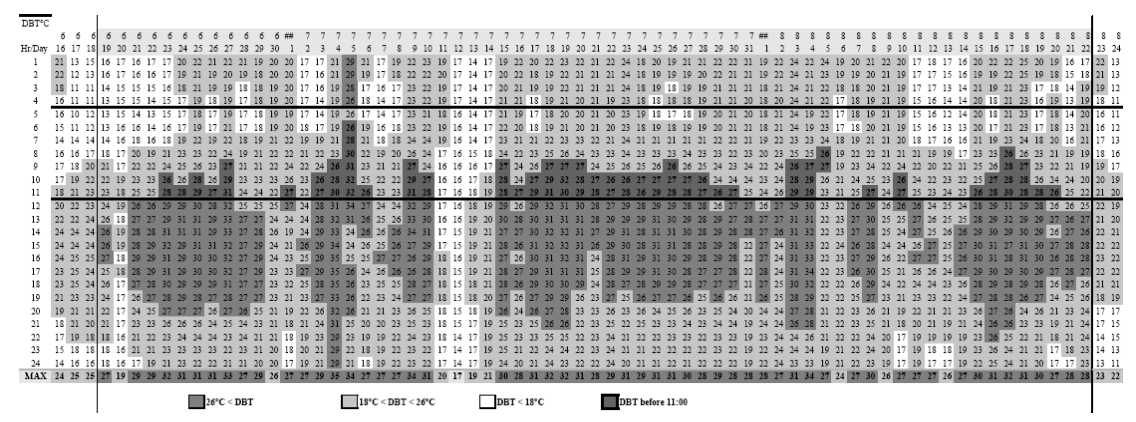

Figure 5: Hourly dry-bulb temperatures, June-August (in degrees, Celsius).

During that period the impact of incident solar radiation on the building and its interior has an added undesirable effect on cooling demands. The maximum DBT for that period is on July $4,35^{\circ} \mathrm{C}$, at $16: 00 \mathrm{Hr}$. Characteristic hourly values of temperature, direct radiation, sun azimuth, and sun elevation for the beginning and end of the period in which the DPT is above the comfort zone, June 19 and August 22, are gathered from weather data available from US Department of Energy [15] and formatted in Weather Tool 2011 [16].

Of significance to our design are only those values with respect the strictly facing east façade. We must eliminate from this dataset values before sunrise and after the sun's rays are no longer hitting directly the façade, i.e. when the south façade is facing the sun and the east façade is in shade. Keeping in mind that our east façade is oriented at $5.24^{\circ} \mathrm{N}$, the range of azimuth $(\mathrm{Az})$ needs to be bigger or equal to the azimuth at sunrise and less or equal to $185.24^{\circ} \mathrm{N}$. Adjusted to the closest hour, for which weather data is available, 84 data points represent the DBT values of direct exposure to solar radiation. Those are between the hours of 5:00 and 11:00. (Figure 5, in dark grey). Figure 6 plots all 84 1-hour periods, for which we have recorded information. Their polynomial distribution is $\mathrm{El}=\mathrm{F}$ $(\mathrm{Az})=-0.0102 \mathrm{Az}^{2}+2.9548 \mathrm{Az}-149.33$, with $\mathrm{R}^{2}=0.8496 .\left(\mathrm{R}^{2}\right.$ is a statistical term saying how good one term is at predicting another. If $\mathrm{R}^{2}$ is 1.0 then given the value of one term, you can perfectly predict the value of another.) 


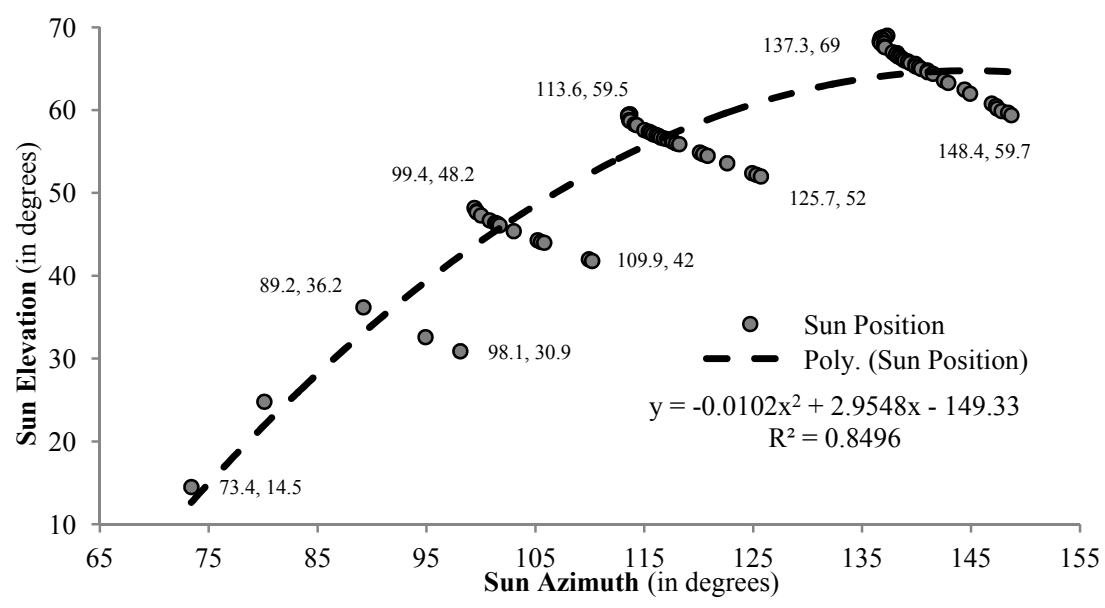

Figure 6: Sun position (Elevation and Azimuth), and adjusted polynomial distribution curve.

\section{Design geometry}

With our predominantly east facing façade a fixed louver or fin system will not perform well throughout the whole day as the altitude of the sun is much lower. Sun light will pass directly under most horizontal shading systems [17].

To overcome this problem one strategy is to use a movable solar shading system. This strategy would introduce computer controlled fins that follow the path of the sun. Achieving this level of control, however, is relatively expensive and dependent on mechanical and electronic devices. With the aid of variable geometry we can achieve similar amount of control with fixed shading devices. By using variable fixed geometry we can combine the efficiency of movable shading systems with the affordability of conventional fixed shading devices. Our use of digital fabrication machines may maintain the same low production cost to variability ratio.

\subsection{Unit design}

Our initial design is comprised of two planar surfaces - one is active and is configured in a plane perpendicular to the direction of the sun (Figure 7, points 1-3-4-5). This surface actively reflects and absorbs the solar radiation and mitigates the majority of the solar stress on the shading system. The other type of surfaces is inactive - it is positioned at $90^{\circ}$ to the active surface, or parallel to the direction of the sun, and has little, if none, exposure to direct solar stress. It however performs inactively by absorbing, reflecting (reflection is the process whereby a surface turns back a portion of the radiation that strikes it [18]) and transmitting indirect radiation from the exterior environment or adjacent shading 
devices. The designed unit maintains a clear opening that is a result of the Sun's altitude and azimuth.
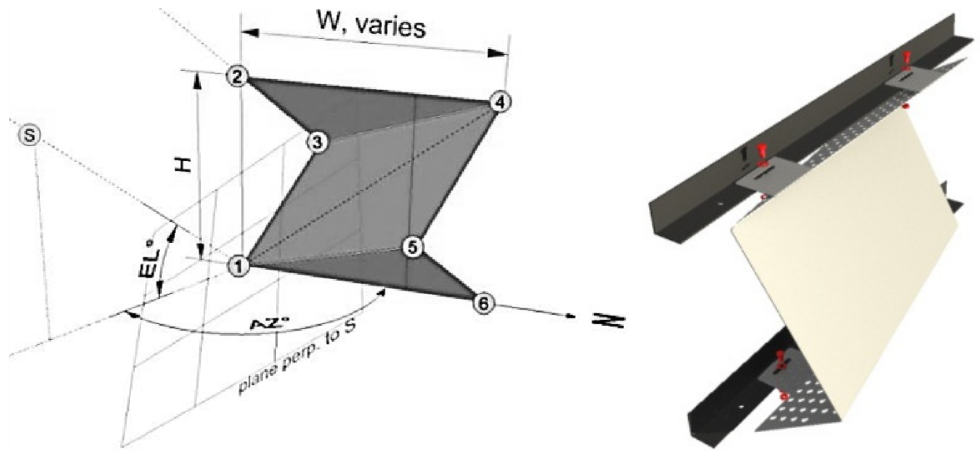

Figure 7: Variable shading unit - geometric definition.

The unit design is developed in the algorithmic modelling tool Grasshopper ${ }^{\circledR}$ and interactively integrates environmental parameters, such as geographic altitude, longitude, and latitude, daily and hourly sun position, and geometric variables, such as desired unit height and orientation (Figure 8). The unit's variable active and inactive surface orientations are a function of $\mathrm{El}$ and $\mathrm{Az}$, and its width is a function of the unit's height.

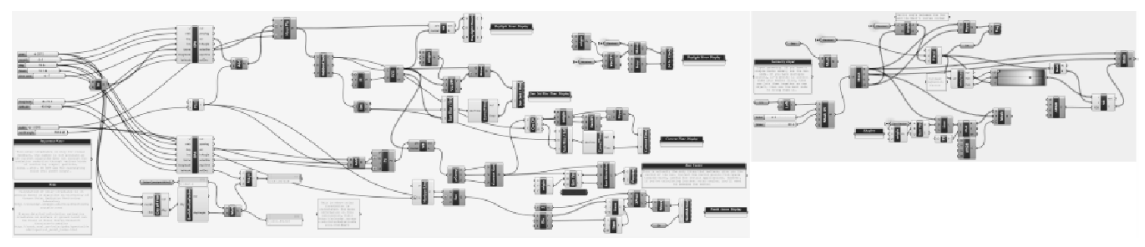

Figure 8: Grasshopper algorithm, screen caption.

Our east-facing glass façade has dimensions of 8"-0" high by 24 "-0" wide, or 96 " 288 ". There are two sets of parameters that control the optimum number of units required for covering the entire 96" 288 " area of the façade. One is the noted above dependency of the shading unit geometry on the solar azimuth and elevation. The other is the length of each unit and the total sum of unit lengths which are parametrically linked to the desired unit height. If the proposed shading device utilizes six 16" high rows of units the total length of all units need be $6 \times 24$ feet, which is 144 linear feet, or 1728 inches.

Using a specifically written in Grasshopper parametric design algorithm, we generate 84 unique shading units based on the 84 previously established unique solar coordinates $(\mathrm{Az}, \mathrm{El})$. We compute that their total length exceeds the above linear 144 feet (288 Inches) of shading units. After a series of trials and errors we conclude that the optimum approach is to balance the number of available units to the sum of their respective heights and widths. 
Using the polynomial distribution from Figure 6 we get a re-distribution of the 84-point dataset to the following 12 points, whose total width, regardless of their order, is 287.962774 inches (Table 1). These will serve as external parameters in the design of our exterior shading device.

Table 1: $\quad$ Redistributed data points.

\begin{tabular}{l|c|c|c|c|c|c|c|c|c|c|c|c|}
\hline $\begin{array}{l}\text { Data } \\
\text { point }\end{array}$ & 1 & 2 & 3 & 4 & 5 & 6 & 7 & 8 & 9 & 10 & 11 & 12 \\
\hline El. & 12.6 & 24.3 & 34.1 & 42.3 & 49.1 & 54.6 & 58.9 & 61.7 & 63.6 & 64.5 & 64.6 & 64.5 \\
\hline Az. & 73.4 & 82.2 & 90.3 & 98.1 & 105.8 & 113.5 & 121.1 & 128.5 & 135.4 & 141.4 & 146.2 & 148.7 \\
\hline
\end{tabular}

These 12 points are used to produce 12 units. Each corresponds to the pair of altitude and azimuth values from Table 1. The unit's consist of a single flat folded surface where the inactive area is perforated for increased porosity. Figure 9 shows six of the 12 units unrolled flat and dimensioned for fabrication.

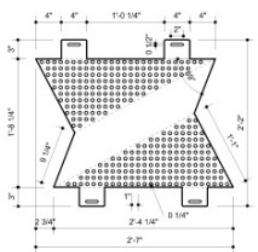

unit 10 Eleanon: 64.5.

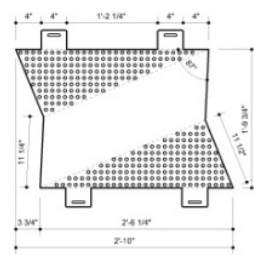

unit 7 conaton 889.

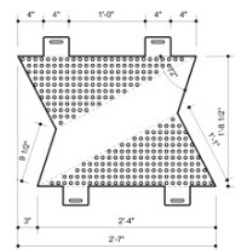

unit 9 Aevason 636

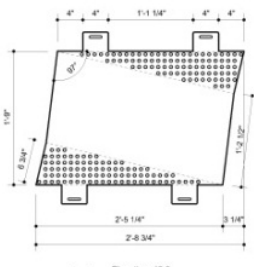

unit 4 Earaton: 23

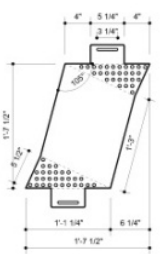

unit 1 Elexton 126

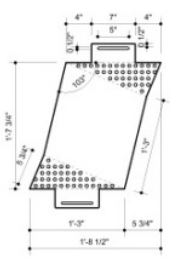

unit 2 ceveron 24.3

Figure 9: $\quad$ Sample of 6 unrolled flat units.

There are almost 480 million permutations of 12 units in a row $(12 !=$ $479,001,600)$ - a number which previously would have been prohibitive for use by the designer. With the help of scripting and computing a series of combinations are generated in which each of the 12 units is utilized once on each row and that number is reduced to 576 unique series of non-repeating 12 units and with no repeating sequences in each row. These 576 rows form 96 sets of 6 rows/12 unit designs.

\subsection{Degrees of visual porosity}

Each of the series is evaluated with respect to percentage of opaqueness, partial openness, and full openness over the areas of the façade where the windows are 
located (Figure 10). The combination with highest percentage of openness is chosen for the prototype proposal (Figure 11).
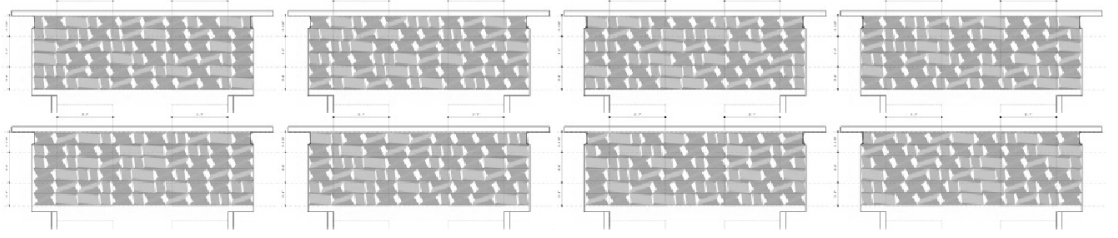

Figure 10: Opacity study, 8 of 96 shown.

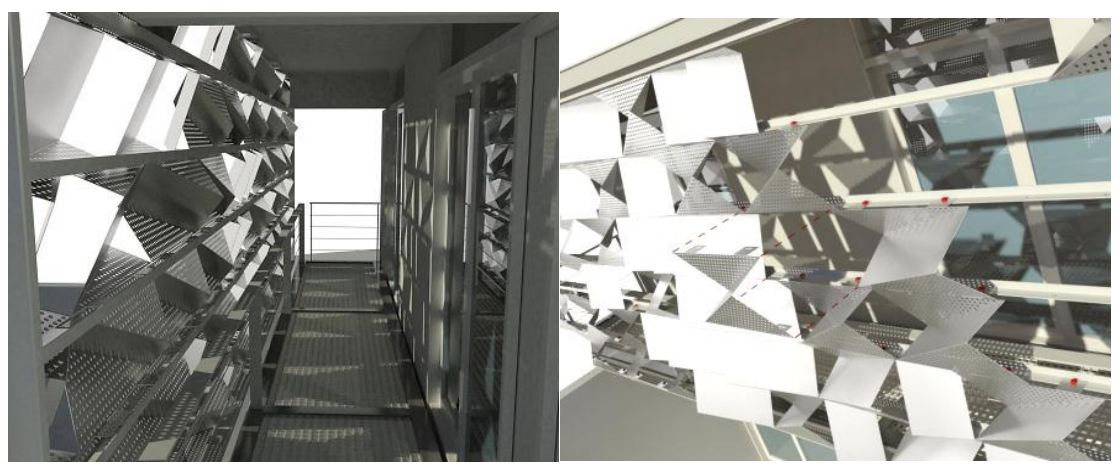

Figure 11: Views of shading design.

\section{Conclusion}

This paper so far has outlined a method of analysis and design that takes into direct consideration environmental parameters, such as sun position and hourly and daily radiation and temperature values. We, however, refrain from claiming that incorporating environmental parameters is sufficient to achieving sensible design. The merit of the final design should only be seen in context of the process that generated it. While introducing shading can play an active and important role in mitigating the negative effect on solar gains during the hot months of the year, the use of the proposed shading device is warranted only during the times of year when the outdoor temperature is above comfort levels. This design method would be more effective in more extreme climates than the one chosen here, where the hot season is extensive and year-round. Further research would be required in optimizing the shading device for maximum solar gains in winter, particularly in cases of being used in colder climates.

Additionally, the building occupancy type, residential, was chosen arbitrarily. The commercial building sector's contribution to the overall demand is projected to increase faster than any other sector, and take over the electricity demand of the residential building sector by 2013 [19]. In reflection of this trend our further design and study will be applied to an office building type. 
It is important at this stage in the project to assert that energy-consumption reducing design criteria are only a part of the demands on the building professions and the consumers to evolve towards a more sustainable future. However, we firmly believe that performance in architecture is a formal property born from a process that simultaneously sites artefact geographically, culturally, critically, as well as engages the process of formal generation and development. This project prioritizes the dependency of design on the site, such as orientation, time, and sun position, program and structure. The emphasis on this dependency is the structuring and organizing principle for the generation and modification of form.

\section{References}

[1] Millard, Bill. Designing the Building-Landscape Interface, Architect, July, pp 56-62, 2011.

[2] US Energy Information Administration (2008), Annual Energy Outlook, www.eia.gov/oiaf/aeo/tablebrowser/

[3] Bader, Stefan. Professional Report: High Performance Façades for Commercial Buildings, University of Texas at Austin, p 9, 2010.

[4] US Energy Information Administration (2011), EIA Annual Energy Outlook, http://www.eia.gov/oiaf/aeo/tablebrowser/

[5] US Energy Information Administration (EIA) http://www.eia.gov lenergyexplained/index.cfm?page=about btu

[6] National Fenestration Rating Council. www.nfrc.org/fenestrationfacts.aspx

[7] Rhinoceros 3D, http://www.rhino3d.com/nurbs.htm

[8] http://amsglossary.allenpress.com/glossary/search?id=radiation1

[9] The Renewable Resource Data Center (RREDC), National Renewable Energy Laboratory (NREL) http://rredc.nrel.gov/solar/glossary/gloss_i.html

[10] RREDC, NREL, Glossary of Solar Radiation Resource Terms, http://rredc.nrel.gov/ solar/glossary/gloss t.html

[11] RREDC, NREL http://rredc.nrel.gov/solar/glossary/gloss_a.html

[12] Bader, Stefan. Professional Report: High Performance Façades for Commercial Buildings, University of Texas at Austin, p 9, 2010

[13] Earth System Research Laboratory, NOAA Solar Calculator, http://www.esrl.noaa.gov/gmd/grad/solcalc

[14] RREDC, NREL http://rredc.nrel.gov/solar/glossary/gloss_d.html

[15] pps1.eere.energy.gov/buildings/energyplus/weatherdata/4_north_and_centr al_america_wmo_region_4/1_usa/USA_PA_Allentown-Lèehigh.V̄alley.Intl. A $\bar{P} .725170-$ TMY $3 . z i p$

[16] Weather Tool ${ }^{\mathrm{TM}}$ 2011, (C) 2010 Autodesk, Inc.Solar Shading Basics, Introduction to Solar Shading, http://www.shadinglouvres.com/solarshading-basics/

[17] Western Regional Climate Center http:/www.wrcc.dri.edu/ams/ glossary.html\#R

[18] US Energy Information Administration (2011), EIA Annual Energy Outlook, http://www.eia.gov/oiaf/aeo/tablebrowser/ 